\title{
Implementation Approaches for Introducing and Overcoming Barriers to Hepatitis B Birth-Dose Vaccine in sub-Saharan Africa
}

\author{
Alix Boisson, ${ }^{a}$ Varun Goel, ${ }^{b}$ Marcel Yotebieng, ${ }^{c}$ Jonathan B. Parr, ${ }^{d}$ Bruce Fried, ${ }^{\text {e Peyton Thompson }}{ }^{f}$
}

\section{Key Findings}

- A review of 39 articles outlining the experience of introducing the hepatitis B birth-dose (HepB-BD) vaccine in low- and middle-income countries in subSaharan Africa identifies the potential barriers to the vaccine's uptake.

- Empirical examples of policy makers targeting the mother's role to increase uptake of HepB-BD vaccine at the community level are strikingly scarce, and efforts to leverage community-level resources and reach remote areas have been limited.

\section{Key Implications}

- We provide solutions that must be adapted to the local context to overcome the barriers to HepB-BD uptake identified across policy, facility, and community levels.

- Synergy must exist between policy, facility, and community level implementation for sub-Saharan African countries to effectively implement a universal HepB-BD vaccine immunization policy.

- For sub-Saharan African country policy makers to effectively implement a universal HepB-BD immunization policy, synergy must exist between the policy-, facility-, and community-level efforts.

\footnotetext{
a Department of Health Policy and Management, Gillings School of Global Public Health, University of North Carolina at Chapel Hill, Chapel Hill, NC, USA.

${ }^{b}$ Department of Geography, University of North Carolina at Chapel Hill, Chapel Hill, NC, USA; Carolina Population Center, Chapel Hill, NC, USA.

' Division of General Internal Medicine, Department of Medicine, Albert Einstein College of Medicine, Bronx, NY, USA.

${ }^{\mathrm{d}}$ Division of Infectious Diseases, Department of Medicine, University of North Carolina School of Medicine, Chapel Hill, NC, USA.

e Department of Health Policy and Management, Gillings School of Global Public Health, University of North Carolina at Chapel Hill, Chapel Hill, NC, USA.

fDivision of Infectious Diseases, Department of Pediatrics, University of North Carolina School of Medicine, Chapel Hill, NC, USA.

Correspondence to Alix Boisson (aboisson@unc.edu).
}

\section{ABSTRACT}

In sub-Saharan Africa (SSA), chronic viral hepatitis B (HBV) affects more than 60 million people. Mother-to-child transmission is a major contributor to the ongoing $\mathrm{HBV}$ epidemic and yet only 11 of $54(20.3 \%)$ SSA countries have introduced the birth dose of $H B V$ vaccine (HepB-BD) into their regular immunization schedule. As more African countries adopt HepB-BD, implementation approaches must be targeted to ensure effective and timely HepB-BD delivery, especially in rural and under-resourced settings. We conducted a systematic literature review of published literature using PubMed. We included 39 articles published from January 2010 to August 2020, as well as gray literature, case studies, and research performed in SSA. We describe barriers to the uptake of HepB-BD in SSA at the policy, facility, and community levels and propose solutions that are relevant to stakeholders wishing to introduce HepB-BD. We highlight the importance and challenge of reaching infants who are born outside of health care facilities (i.e., home deliveries) with HepB-BD in partnership with community health workers. We also discuss the critical role of maternal education and community engagement in future HepB-BD scale-up efforts in SSA.

\section{INTRODUCTION}

C ix years after the World Health Organization (WHO) African Regional Committee convened to develop a hepatitis elimination strategy, hepatitis B virus (HBV)related mortality remains high at 200,000 deaths per year in sub-Saharan Africa (SSA). ${ }^{1,2}$ The committee identified the prevention of HBV in children as a priority, aspiring to lower seroprevalence of hepatitis B surface antigen-positivity among children aged younger than 5 years to less than $2 \%$ by 2020 and less than $0.1 \%$ by $2030 .^{3}$

Mother-to-child transmission (MTCT) is a significant driver of the ongoing HBV epidemic. HBV exposure at a young age is associated with more severe liver disease; if infected at birth, an infant has a 70\%-90\% chance of developing chronic HBV. ${ }^{4,5}$ The WHO estimates that chronic $\mathrm{HBV}$ affects more than 100 million individuals in the African region. ${ }^{4}$ It has been estimated that over 350,000 infants are infected annually via MTCT in the African region. ${ }^{6}$ Thus, preventing MTCT of HBV is a cornerstone of effective strategies against the HBV epidemic in SSA. The 


Despite the
availability of the
HBV vaccine since
1982 , few SSA
countries
administer the
birth-dose
vaccination due to
implementation
challenges and a
lack of HBV
burden

awareness.

Advocates, policy
makers, and other
stakeholders
working to change
national vaccine
policy must
address the
barriers of lack of
political will and
insufficient
evidence.

Advocates, policy makers, and other stakeholders national vaccine policy must address the barriers of lack of political will and evidence. birth dose of HBV vaccine (HepB-BD) is the most effective $(>95 \%)$ prevention measure against MTCT if administered within 24 hours of birth ${ }^{7,8}$ and followed by completion of 2 or 3 routine immunizations. ${ }^{9}$ Despite the availability of the HBV vaccine since 1982, few SSA countries administer the birth-dose vaccination due to implementation challenges and a lack of HBV burden awareness. $^{10}$

The global health community understands the importance of the HepB-BD vaccine, which has led to Gavi, the Vaccine Alliance sponsoring distribution costs for the HepB-BD vaccine across SSA. ${ }^{1,12}$ Though these efforts are ongoing, as of April 2021, only 13 of 48 countries (27\%) in SSA have introduced HepB-BD, ${ }^{13}$ falling short of the WHO Africa Regional Committee goal of at least 25 countries by the end of $2020^{3}$ (Figure). ${ }^{13-14}$ A majority of SSA countries still use the standard HBV vaccine schedules ( 3 doses of hepatitis B vaccine), typically given at 6, 10, and 14 weeks of life. Although this schedule is practical, immunizing infants beginning at 6 weeks does not prevent vertical transmission from $\mathrm{HBV}$-infected mothers to their infants.

Barriers to HepB-BD implementation in SSA exist across the supply chain and care continuum. Key barriers include lack of evidence of HBV seroprevalence and rates of MTCT, financial costs of vaccine distribution, insufficient cold-chain storage, lack of trained community health workers (CHWs), and a high proportion of at-home births. ${ }^{4}$ Given these challenges, HepB-BD implementation practices must be in place alongside vaccine distribution to ensure effective vaccine delivery, especially in rural and under-resourced settings. We discuss existing determinants of HepB-BD uptake in SSA countries at the policy, facility, and community levels and propose solutions for stakeholders to introduce HepB-BD in low- and middle-income countries (LMICs). While the literature often discusses solutions at the policy and facility levels, we argue that researchers and stakeholders should place more emphasis on community-level interventions, especially in highly rural contexts.

\section{METHODS}

Iterative scoping reviews were performed using PubMed to identify articles published between January 2010 and August 2020 that discussed methods for country-level implementation of HepB-BD. We used the following key terms in the search: "hepatitis B birthdose vaccination," "HepB-BD," "hepatitis B birth dose vaccination," "hep b birthdose," and "HBV birth dose vaccination." Because immunization system implementation science is relevant to HepB-BD implementation efforts in LMIC settings, we also reference this broader swath of the scientific literature. Literature was drawn only from articles published after 2010 to maintain relevance, as evidence-based immunization implementation science is a fast-developing field. In addition to articles identified through PubMed, we also extracted findings from gray literature, case studies, and research performed in SSA, but we expanded the search to Southeast Asia (SEA), in part due to the successful introduction of HepB-BD in SEA.

\section{RESULTS}

In all, 598 reports were identified, and 39 were relevant and reviewed for this publication (Table 1 and Supplement). To be included, articles had to describe research introducing the HepB-BD within an LMIC or data-backed guidance for the inclusion of HepB-BD. Of articles included, 13 reports focused solely on SSA. We categorize vaccine uptake determinants in 3 domains with immediate relevance to HepB-BD implementation: policy-, facility-, and community-level barriers and solutions. Major themes, barriers, and solutions are outlined in Table $2 .^{15-32}$

\section{Policy Level}

The first step toward HepB-BD implementation requires the development of clear policy recommendations and changing national vaccine schedules to include HepB-BD. Advocates and other stakeholders must first synthesize setting-specific evidence of HBV prevalence and solutions. Next, policy makers and other relevant players must be engaged to convey the need for HepB-BD and relevant policy change. These efforts must address 2 persistent barriers to national policy change: a lack of political will and insufficient evidence.

\section{Lack of Political Willingness: Advocacy}

Countries often lack the political will to enact policies that mandate HepB-BD within 24 hours of birth, ensure vaccine availability at every facility, and ensure an adequate supply chain of HepBBD. ${ }^{33}$ A lack of awareness of the vaccine's effectiveness and insufficient advocacy for HepB-BD often contribute to the policy-level determinants. Vaccine supporters can foster political will by engaging relevant stakeholders, decision makers, and effective in-country advocacy 
FIGURE. Choropleth Map Demonstrating Hepatitis B Birth-Dose Vaccine Coverage and Hepatitis B Surface Antigen Prevalence in sub-Saharan Africa ${ }^{a}$

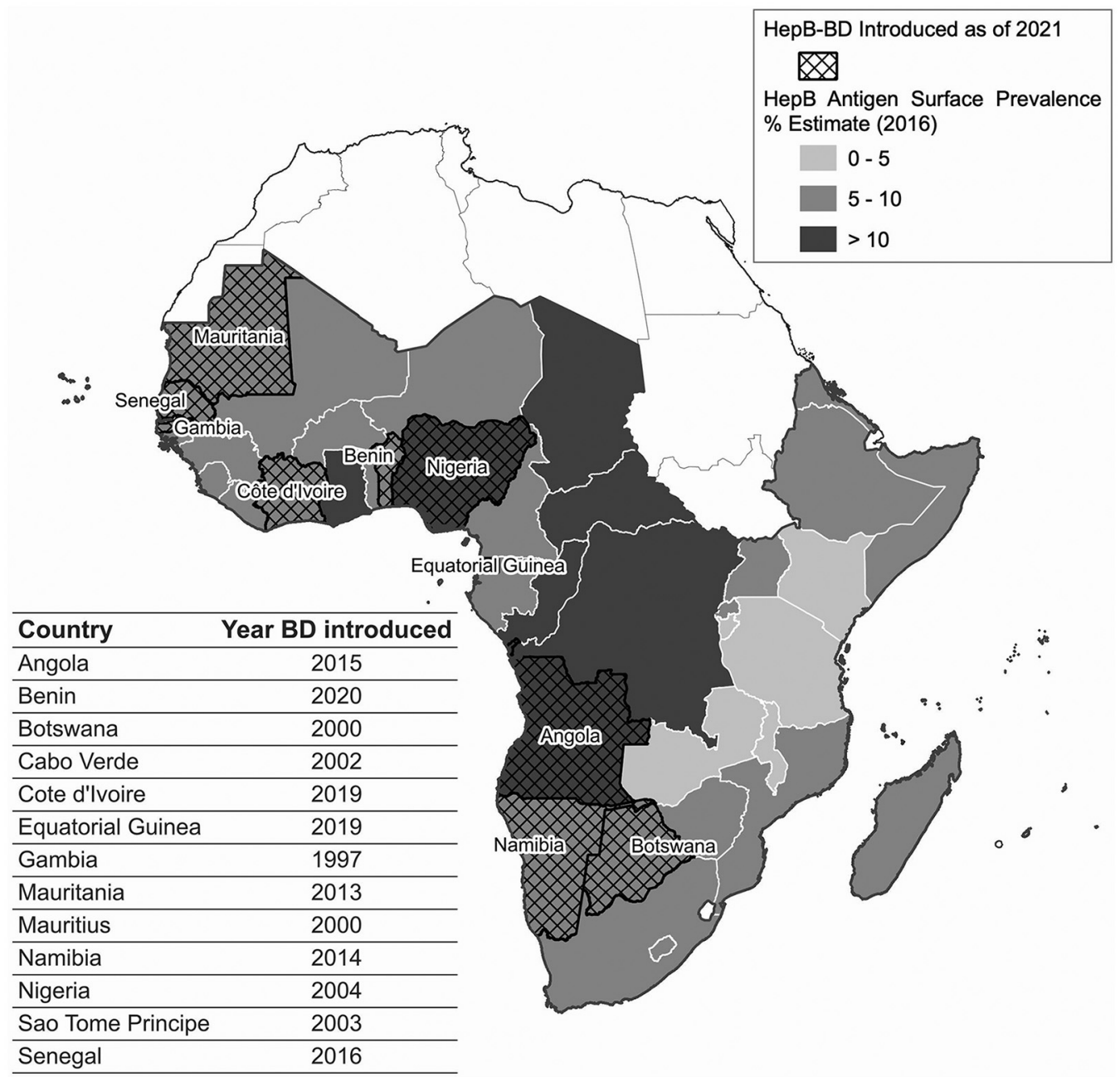

Abbreviations: HepB-BD, hepatitis B birth dose; $\operatorname{Hep~B,~hepatitis~B;~BD,~birth~dose.~}$

a This figure presents the countries in sub-Saharan Africa (SSA) that have introduced the birth dose of HBV vaccine (HepB-BD) and estimates of HepB antigen surface prevalence by country. SSA islands not depicted in the map include Cabo Verde, Comoros, Mauritania, Mauritius, São Tomé and Principe, and Seychelles. The table lists the year of HepB-BD introduction for all SSA countries offering the vaccine by 2021 . All classification intervals are left closed and right open. Geographical boundaries obtained from Global Administrative Areas version 3.6.

Source: Razavi-Shearer et al.; Niuguna.

groups across all health care systems and socioecological levels.

Engaging a united interdisciplinary group of stakeholders is more effective for supporting multilevel HepB-BD implementation efforts to address existing barriers. Primary stakeholders may include ministries of health and finance, donor agencies, external academic and nongovernmental or multilateral organizations involved in the programming, and drug manufacturers. Relevant literature also stresses the importance of other groups in achieving political commitment for incountry HepB-BD uptake, such as professional societies, medical associations, and community and religious leaders. ${ }^{34}$

São Tomé and Príncipe and Nigeria demonstrated success by calling on the private health sector, physicians and nurses, and hepatology associations 
TABLE 1. Hepatitis B Birth Dose Vaccine Uptake Themes Discussed in the Empirical Literature ( $N=39$ )

\begin{tabular}{|c|c|c|c|c|}
\hline & $\begin{array}{l}\text { Sub-Saharan } \\
\text { Africa Specific }\end{array}$ & $\begin{array}{l}\text { Policy- } \\
\text { Level }\end{array}$ & $\begin{array}{c}\text { Facility- } \\
\text { Level }\end{array}$ & $\begin{array}{c}\text { Community- } \\
\text { Level }\end{array}$ \\
\hline Breakwell et al., $2017^{4}$ & $x$ & $x$ & $x$ & $x$ \\
\hline Reardon et al., $2019^{9}$ & $x$ & $x$ & $x$ & \\
\hline Spearmen et al., $2017^{10}$ & $x$ & & $x$ & $x$ \\
\hline Dionne-Odom et al., $2018^{11}$ & $x$ & $x$ & $x$ & $x$ \\
\hline Nelson et al., $2016^{12}$ & & $x$ & $x$ & $x$ \\
\hline Boa et al., $2017^{15}$ & $x$ & $x$ & & \\
\hline Chang et al., $2019^{16}$ & & & $x$ & \\
\hline Ginzberg et al., $2018^{17}$ & & $x$ & $x$ & \\
\hline Hambridge et al., $2019^{18}$ & $x$ & $x$ & & \\
\hline Howell et al., 2014. ${ }^{19}$ & $x$ & $x$ & $x$ & \\
\hline Jourdain et al., $2019^{20}$ & & $x$ & $x$ & \\
\hline Kolwaite et al., $2016^{21}$ & & & & $x$ \\
\hline \multicolumn{5}{|l|}{ Mak et al., $2018^{22}$} \\
\hline Miyahara et al., $2016^{23}$ & $x$ & & $x$ & $x$ \\
\hline Nayagam et al., $2016^{24}$ & & $x$ & $x$ & \\
\hline Nayagam et al., $2016^{25}$ & & $x$ & $x$ & \\
\hline Nguyen et al., $2019^{26}$ & & & & $x$ \\
\hline Pham et al., $2018^{27}$ & & & $x$ & \\
\hline Scott et al., $2018^{28}$ & & $x$ & & \\
\hline Sobel et al., $2011^{29}$ & & $x$ & $x$ & \\
\hline Spearman, $2018^{30}$ & & $x$ & & $x$ \\
\hline Wiesen, et al., $2016^{31}$ & & $x$ & & \\
\hline World Health Organization, $2019^{32}$ & & $x$ & $x$ & $x$ \\
\hline Okenwa et al., $2019^{33}$ & $x$ & $x$ & $x$ & $x$ \\
\hline Breakwell et al., $2017^{34}$ & & & $\mathrm{x}$ & $x$ \\
\hline Moturi et al., $2018^{35}$ & $x$ & & $X$ & $x$ \\
\hline Awuku and Yeboah-Afihene, $2018^{36}$ & $x$ & $x$ & $x$ & \\
\hline Tamandjou et al., $2017^{37}$ & $x$ & $x$ & $X$ & $\mathrm{x}$ \\
\hline Hagan et al., $2019^{39}$ & & $x$ & $x$ & \\
\hline Anderson et al., $2018^{40}$ & $x$ & $x$ & $x$ & \\
\hline Beigi et al., $2014^{47}$ & & & & $\mathrm{x}$ \\
\hline Li et al., $2017^{52}$ & & & $x$ & $\mathrm{x}$ \\
\hline Lemoine, Thursz, $2017^{56}$ & $x$ & $x$ & & \\
\hline Centers for Disease Control and Prevention, $2013^{57}$ & & & $\mathrm{x}$ & $\mathrm{X}$ \\
\hline Pham et al., $2019^{59}$ & & & & $\mathrm{X}$ \\
\hline Giao et al., $2019^{60}$ & & & & $x$ \\
\hline Woodring et al., $2019^{62}$ & & & $\mathrm{X}$ & $\mathrm{X}$ \\
\hline Xeuatvongsa et al., $2016^{64}$ & & & & $\mathrm{X}$ \\
\hline Wiesen et al., $2016^{68}$ & & & $\mathrm{X}$ & $x$ \\
\hline
\end{tabular}


TABLE 2. Potential Barriers to and Solutions to Hepatitis B Birth-Dose Vaccine Uptake in Sub-Saharan Africa Countries

\begin{tabular}{|c|c|c|c|}
\hline Intervention Level & Determinant & Potential Barriers & Potential Solutions \\
\hline \multirow[t]{3}{*}{ Policy } & $\begin{array}{l}\text { Lack of political willing- } \\
\text { ness: advocacy }\end{array}$ & $\begin{array}{l}\text { Lack of awareness of impor- } \\
\text { tance of vaccine }\end{array}$ & $\begin{array}{l}\text { Engage relevant stakeholders, decision makers, and } \\
\text { effective in-country advocacy groups }\end{array}$ \\
\hline & $\begin{array}{l}\text { Lack of political willing- } \\
\text { ness: affordability }\end{array}$ & Lack of available resources & Provide cost-effective examples in sub-Saharan Africa \\
\hline & $\begin{array}{l}\text { Need for effective } \\
\text { recommendations }\end{array}$ & $\begin{array}{l}\text { Lack of consensus recommen- } \\
\text { dations for vaccine } \\
\text { implementation }\end{array}$ & $\begin{array}{l}\text { Develop site-specific recommendations that draw upon } \\
\text { research and literature, international guidelines, and } \\
\text { feedback from diverse stakeholders }\end{array}$ \\
\hline \multirow[t]{11}{*}{ Facility and Logistics } & \multirow[t]{4}{*}{$\begin{array}{l}\text { Knowledge and training } \\
\text { of health workers }\end{array}$} & \multirow{3}{*}{$\begin{array}{l}\text { Lack of awareness of vaccine } \\
\text { benefits, stigma, and gaps in } \\
\text { knowledge among CHWs }\end{array}$} & $\begin{array}{l}\text { Educate facility staff on the HepB-BD vaccine and ad- } \\
\text { ministration protocol }\end{array}$ \\
\hline & & & $\begin{array}{l}\text { Completion of checklist form by staff before discharge } \\
\text { of newborn }\end{array}$ \\
\hline & & & Couple immunization with BCG and oral polio vaccine \\
\hline & & $\begin{array}{l}\text { Variable vial size and concern } \\
\text { for wastage }\end{array}$ & Make available vial size combinations \\
\hline & \multirow[t]{3}{*}{$\begin{array}{l}\text { Short window for ad- } \\
\text { ministering vaccine }\end{array}$} & 24-hour administration window & $\begin{array}{l}\text { Keep mothers in delivery ward at least } 24 \text { hours after } \\
\text { delivery }\end{array}$ \\
\hline & & \multirow{2}{*}{$\begin{array}{l}\text { Mother's hesitancy to vaccinate } \\
\text { infant }\end{array}$} & Administer vaccine in delivery ward \\
\hline & & & Mitigate cost burden \\
\hline & Cost burden & User fees for vaccines & $\begin{array}{l}\text { Subsidize or reduce costs associated with regular } \\
\text { immunization }\end{array}$ \\
\hline & \multirow{3}{*}{$\begin{array}{l}\text { Vaccine storage and } \\
\text { stockouts }\end{array}$} & $\begin{array}{l}\text { Limited storage space and } \\
\text { stock-out determinants }\end{array}$ & $\begin{array}{l}\text { Allow private providers to obtain the vaccine free-of- } \\
\text { charge }\end{array}$ \\
\hline & & $\begin{array}{l}\text { Poor communication between } \\
\text { the immunization and maternity } \\
\text { wards }\end{array}$ & Establish standing orders for the vaccine \\
\hline & & $\begin{array}{l}\text { Reaching remote rural villages } \\
\text { with vaccines }\end{array}$ & Cultivate partnerships with vaccine distributor \\
\hline \multirow[t]{4}{*}{ Community } & \multirow[t]{4}{*}{ Maternal involvement } & \multirow[t]{2}{*}{ At-home births } & Leverage post-home birth visit to administer vaccine \\
\hline & & & Raise vaccine awareness within the community \\
\hline & & \multirow{2}{*}{$\begin{array}{l}\text { Geographic distance inhibiting } \\
\text { timely delivery of newborn to } \\
\text { health facility }\end{array}$} & Educate mothers during antenatal care visits \\
\hline & & & Families to keep home-based records \\
\hline
\end{tabular}


TABLE 2 Continued

\begin{tabular}{|c|c|c|c|}
\hline Intervention Level & Determinant & Potential Barriers & Potential Solutions \\
\hline & \multirow[t]{4}{*}{$\begin{array}{l}\text { Community health } \\
\text { worker involvement }\end{array}$} & \multirow[t]{4}{*}{$\begin{array}{l}\text { Poor communication channels } \\
\text { between } \mathrm{CHW} \text { and mothers }\end{array}$} & $\begin{array}{l}\text { Perform home visits in rural communities to educate } \\
\text { mothers, track pregnancies, and refer mother-infant } \\
\text { pair to nearby facilities }\end{array}$ \\
\hline & & & Provide at-home immunization for infants \\
\hline & & & Strengthen ties between $\mathrm{CHWs}$ and facilities \\
\hline & & & Provide incentives for $\mathrm{CHWs}$ \\
\hline & \multirow{2}{*}{$\begin{array}{l}\text { Evidence-based innova- } \\
\text { tions to reach } \\
\text { communities }\end{array}$} & \multirow[t]{2}{*}{$\begin{array}{l}\text { Vaccine refrigeration } \\
\text { requirements }\end{array}$} & $\begin{array}{l}\text { Use of out-of-cold-chain or controlled temperature } \\
\text { chains }\end{array}$ \\
\hline & & & $\begin{array}{l}\text { Mobile-based devices to track pregnancies in rural } \\
\text { areas }\end{array}$ \\
\hline
\end{tabular}

Abbreviations: BCG, Bacillus Calmette-Guerin; CHW, community health worker; HepB-BD, hepatitis B birth dose.

\section{Advocacy among decision makers for national policies to mandate the delivery of HepB- BD within the 24- hour requirement and the pre- positioning of vaccines in the maternity wards are both critical to ensuring high uptake of the vaccine.}

in advocacy efforts to steer the government towards introducing HepB-BD. ${ }^{35,36}$ Although stakeholder buy-in is crucial in any setting, country-specific groups and associations differ by context, and setting-specific partners should be identified and supported. This collaborative approach is required to develop an effective and sustainable intervention with HepB-BD champions at every socioecological level. To achieve uptake, stakeholders should understand the importance of advocating alongside partners in different but related sectors such as cancer prevention disease-specific advocacy groups ${ }^{4,37}$ or safe motherhood care. Strengthening the case for universal HepB-BD by engaging diverse stakeholders will press decision makers to pledge political commitment.

Finally, advocacy among decision makers for national policies to mandate the timely delivery of the vaccine within the 24-hour requirement and the pre-positioning of vaccines in the maternity wards are both critical to ensuring high uptake of HepB-BD. A study in Nigeria provided recommendations for improving $\mathrm{HepB}-\mathrm{BD}$ uptake among infants. ${ }^{33}$ During the time of the study, national-level policy makers in Nigeria had not introduced a policy mandate. While the National Primary Health Care Development Agency in Nigeria recommends that all infants receive HepB-BD, the immunization window ranges from the birth of the newborn to 2 weeks of age. One of the study's primary recommendations was to mandate a policy for HepB-BD immunization of newborns within 24 hours of delivery. Compared to a similar study in the Philippines that had introduced a policy mandating infant immunization within the 24-hour window, the uptake of HepB-BD in Nigerian hospitals $(26.2 \%)$ was much lower than in the Philippines hospitals $(87 \%) .^{33}$

\section{Lack of Political Willingness: Affordability}

In addition to advocacy, affordability and costeffectiveness are key determinants of political willingness. Deceleration of vaccine uptake occurs due to financial uncertainty or concern over the availability of resources. ${ }^{37}$ Quantitative impact estimates are recommended for policy makers, as they solidify plans for start-up, maintenance, and opportunity costs. Cost-effectiveness and scalability analyses can be achieved using models derived from country-specific pilot studies or similar studies from neighboring countries.

Experience from other SSA countries can be used to demonstrate a favorable return on investment. Preliminary research confirms the affordability of HepB-BD, which costs only US\$0.20 per 10-dose vial, making it one of the least expensive vaccines available. ${ }^{1,34,36,38}$ Various studies analyze the affordability of HepB-BD both in SSA and in SEA. ${ }^{9,39}$ A notable study comparing 3 strategies of universal HepB-BD, targeted HepB-BD, and the pentavalent vaccine only indicated that the addition of a universal HepB-BD prevented the largest number of additional MTCT cases and was the preferred strategy at a willingness-to-pay threshold of US\$150 per infection prevented. ${ }^{40}$ Success stories from other SSA countries are also 
useful in achieving political commitment because they demonstrate clear return-on-investment through sustained improvements in coverage rates following policy change. Empirical successes include the introduction of HepB-BD into the Gambia in the 1990s, Botswana in the 1990s, Namibia in 2014-2015, and São Tomé and Príncipe in $2019 .^{35,39}$

The vaccine's scalability improves returns ${ }^{9,39}$ but also introduces challenges in building adequate vaccine reserves and meeting costs of large-scale distribution. A solution is to apply for sponsorship from Gavi, ${ }^{1,12}$ support that is especially important when a government lacks budgetary flexibility. During the coronavirus disease (COVID-19) pandemic, donors' financial commitments have shifted from noncommunicable to infectious diseases, especially in LMICs. Countries around the world may turn to LMICs to guide how best to tackle infectious diseases. While global stakeholders are recognizing the risk of communicable diseases, maintaining regular vaccinations is now more critical than ever to avoid the emergence of twin epidemics. The time is right to secure funding for the roll-out of the HepB-BD now to pilot a successful vaccine distribution initiative that can serve as an example for future large-scale COVID-19 vaccine campaigns.

\section{Need for Effective Recommendations}

Consensus recommendations for HepB-BD implementation are lacking but necessary to translate political will into effective action. We suggest developing site-specific recommendations that draw upon research and literature, international guidelines, ${ }^{41}$ and feedback from diverse stakeholders, including people living with $\mathrm{HBV} .{ }^{42}$ We propose 2 ingredients for building a strong recommendation: a well-constructed strategy based on local experience and the application of knowledge gleaned from implementation theory perspectives. It is crucial to develop a comprehensive implementation strategy from the outset that is grounded in theory and uses the latest innovations to overcome any barriers to HepB-BD uptake. ${ }^{43}$ Public health policies and practices disseminated by WHO are a logical starting point and are guided by the most comprehensive health research knowledge to improve global health worldwide. ${ }^{4,45}$ Additionally, research from neighboring and comparable settings should be used to develop recommendations. ${ }^{41}$ Finally, implementers should continuously revisit and evaluate HepB-BD recommendations to incorporate recent innovations and improve any implementation determinants. ${ }^{46}$

\section{Facility Level and Logistics}

The primary delivery method for HepB-BD is health facilities, which include public hospitals, clinics, health centers, and private health facilities. Given the diversity of settings where HepB-BD might be delivered, attention should be given to setting-specific challenges such as lack of community health workers' (CHW) knowledge/training on HBV and prevention through vaccination, logistical challenges in administering the vaccine within 24-hours of birth, difficulty in tracking newborn vaccine status, vaccine stock-outs, systemic vaccine stigma, local opportunity costs, and the negative impact of user fees for immunizations.

\section{Knowledge and Training of Health Workers}

Provider-level HepB-BD knowledge in health facilities is an essential driver of vaccine uptake. Knowledge may be lacking at 2 levels: recognizing the benefits of HepB-BD and general training for timely administration of the vaccine. ${ }^{35,47}$ Lack of awareness of vaccine benefits, stigma, and gaps in knowledge among CHWs, as well as variable vial size and concern for wastage, may hinder HepBBD uptake. ${ }^{35,47}$

One solution to address the lack of awareness and overcome stigma about HepB-BD is educating staff on the vaccine's benefits and shortcomings. Sharing success stories demonstrating HepB-BD's effectiveness can educate and motivate facility staff and cultivate HepB-BD champions. ${ }^{47}$ Data should be shared on the only reported negative consequence of HepB-BD-an anaphylactic reaction caused by previous HBV exposure-which rarely occurs after about 1 in 1 million doses of the vaccine. ${ }^{35}$ Alleviating any fear or bias against vaccinating newborns and ensuring provider buy-in is critical for introducing HepB-BD in their communities and ensuring its sustainability.

While HepB-BD's narrow time window may reduce provider willingness to adopt the vaccine, providing straightforward written guidelines, conducting initial and refresher training, and providing supportive supervision can ease the burden of the vaccine's specific logistical challenges. ${ }^{35}$ Training should occur in all facilities within a community-whether public or privately operated. The complete multidisciplinary workforce should be involved to ensure vaccine coverage for all involved in the training/vaccination process in anticipation of wide-scale distribution. ${ }^{34,35}$ Training

\section{Provider knowledge may be lacking at 2 levels: recognizing the benefits of HepB- $B D$ and general training for timely administration of the vaccine.}


objectives may include assigning vaccine-related duties to a specific role. A study in China determined the success of a strategy incorporating the vaccine-administration role to the obstetrician, clearing up potential confusion in terms of vaccination responsibilities. ${ }^{34,35}$ A Nigerian study found that vaccine oversights were vastly avoided when staff completed a vaccine-related checklist before discharging mother-infant pairs. ${ }^{35}$ Finally, staff may be trained to streamline the HepB-BD vaccine with the vaccines for $\mathrm{TB}$ and polio to improve timely vaccination. To date, 4 SSA-based studies have assessed the effect of all 3 vaccines outside of the 24-hour window, 5 studies have measured the rate of individual vaccine uptake within 24 hours of delivery, but no study has evaluated the effect of streamlining the 3 vaccines at birth. ${ }^{48}$ The WHO confirms that the 3 vaccines do not interfere with one another's immune responses. ${ }^{45}$ Since the facility already offers one or both vaccines, health staff may leverage existing training experience for administering HepBBD. ${ }^{45}$

Another challenge to administering the vaccine in the 24-hour window is the various vial sizes (single-, 2-, 6-, 10-, or 20-dose vials). ${ }^{45}$ In the case of a small number of deliveries within a given period, facility staff often wait to open multidose vials to avoid wastage. To address this issue, vaccine suppliers could consider making available a combination of single-dose and multidose vials, such that vial size would be appropriate for both smaller facilities with fewer daily deliveries and larger facilities with multiple daily deliveries. Facility staff should receive training on a protocol specific to their facility's volume of deliveries and vial sizes. Some would argue that vials should be opened regardless of concerns for wastage because the benefits of timely vaccination far outweigh the risk of wastage.

\section{Short Window for Administering Vaccine}

The HepB-BD vaccine's short window for administration is perhaps its greatest implementation challenge. Administering timely vaccine is difficult for births that occur in facilities. It is even more pronounced for infants born outside of facilities (see discussion of at-home births in the community-level section). Maternal hesitancy and lack of awareness of HBV and the HepB-BD may further complicate efforts to administer timely infant vaccination in facilities. A mother's hesitancy may be due to general or HepB-BD-specific vaccine hesitancy, cost, or other factors, but the short window for vaccine administration requires an effective approach to generating mother buy-in quickly.

The WHO suggests keeping mothers in the delivery ward for at least 24 after their child's birth, a practice not widely adopted in SSA health facilities. ${ }^{35}$ A study in São Tomé and Príncipe reported combining 2 approaches: for mother-infant pairs to remain in the postnatal ward for longer than 1 day and to offer vaccines in the maternity ward for on-site vaccination. This joint approach yielded improved accessibility, greater convenience, and increased HepB-BD uptake. ${ }^{35,39}$

\section{Cost Burden}

Cost is a critical barrier to consumer uptake (in addition to the previously discussed affordability consideration on a national level) that must be carefully addressed. User fees may prevent families from taking their newborns to receive vaccinations at higher-quality or preferred facilities. While vaccines in many countries are provided free-of-charge to facilities, most providers request a payment for a vaccination card to cover administrative and workforce costs for immunization services and monitoring during the infant's first year of life. ${ }^{49}$

Removing monetary barriers through small cash incentives or reducing user fees for immunization can improve uptake in the short-term, ${ }^{49,50}$ though it may not be a sustainable long-term option. A study in the Democratic Republic of the Congo demonstrated that uptake of the rotavirus vaccine was $99 \%$ if the vaccine was provided free of charge. ${ }^{51}$ In the long term, policy makers may consider using national- or district-level budgets to subsidize administrative costs accrued by facilities to improve regular immunization rates among infants.

\section{Tracking Systems}

The current SSA practice for complete immunization following HepB-BD includes 3 additional doses of the HBV vaccine at 6,10 , and 14 weeks of life. A country's administrative capacity for tracking an infant's immunization progress may obstruct the vaccine's success. ${ }^{4,35}$ A review that included SSA countries currently administering HepB-BD reported that the vaccine's documentation is suboptimal across the continent. ${ }^{4}$ A lack of adequate reporting infrastructure (data health information systems) ${ }^{34}$ and failure to comply with vaccine recording by facility staff may explain these findings.

The tracking system may be improved by standardizing all HepB-BD-related immunization- 
reporting tools, such as immunization cards, registers, and data management systems, to include HepB-BD-specific administration details. Tracking of doses administered also helps to inform supply management of HepB-BD at the facility level. ${ }^{45}$ The use of standardized tools can calibrate and improve data monitoring efforts in LMICs. $^{34}$ Furthermore, monitoring and evaluation systems must be in place to ensure that health workers are appropriately using the developed tracking tools. Training, protocol utilization, and regular assessment of health worker compliance in tracking vaccinations can increase compliance of vaccine documentation across the country.

\section{Vaccine Storage and Stock-Outs}

Health facility administrators should safeguard access to vaccines by addressing both limited storage space and stock-out determinants. Botswana, The Gambia, Mauritania, Namibia, and Nigeria reported stock-outs and limited vaccine sessions as barriers to timely access and administration of HepB-BD. ${ }^{4,33}$ Poor communication between the immunization and maternity wards can further hinder vaccine logistics at the facility level. ${ }^{33}$ A final logistical barrier is reaching remote rural villages with vaccines. ${ }^{37,52}$

Solutions to vaccine stock-outs and limited vaccine sessions include storing the vaccine in existing cold chains, preferably in labor wards, establishing standing orders for the vaccine, and leveraging partnerships with vaccine distributors. ${ }^{51}$

Facilities can use existing storage space or store HepB-BD in the labor ward. Health officials in many SSA countries already recommend that infants receive the Bacillus Calmette-Guerin (BCG) and oral polio vaccines at birth, and both have achieved high rates of uptake. ${ }^{49}$ Storage space in health facilities may therefore already exist, and introducing HepB-BD to the existing cold-chain storage unit may not prove to be a significant disruption. ${ }^{35,36}$ One study in the Democratic Republic of the Congo leveraged the existing Expanded Programme on Immunization cold-chain infrastructure to provide HepB-BD but uncovered challenges in delivering the vaccine in a timely manner. ${ }^{51}$ A São Tomé and Príncipe study demonstrated that storing the HepB-BD in labor wards is another effective approach to increase HepB-BD rates. ${ }^{39}$ However, this may prove a challenge in some settings where maternity wards are not equipped for vaccinespecific storage requirements. Therefore, effective communication and coordination are needed between immunization clinic staff and maternity staff to ensure that infants receive timely vaccination.
National mandates to vaccinate in maternity wards could help facilities and staff to shift birth-dose administration from immunization clinics to maternity wards.

SSA countries that currently administer HepBBD also reported stock-outs as an implementation barrier. A solution to frequent stock-outs employed in the Western Pacific was establishing standing orders for HepB-BD with the manufacturer. ${ }^{11,34}$ Vaccine rates increased due to regular shipments of HepB-BD in place of need-based shipments.

Finally, a public-private partnership with Gavi can facilitate logistics, avoid stock-outs, and lower vaccine costs. ${ }^{36}$ Gavi has overseen the distribution of many vaccines, including HepB-BD, across the globe and can therefore provide empirical knowledge of supply and logistics for recent adopters of HepB-BD. In addition, national vaccination initiatives are advised to partner with private facilities where a substantial portion of deliveries occur to allow private providers to obtain routine HepB$\mathrm{BD}$ free-of-charge, in line with public providers. The Democratic Republic of the Congo provides vaccines for free through public, private, and faith-based facilities to increase immunization reach. ${ }^{53}$ In the Philippines, $20 \%$ of deliveries occur in private facilities, so private providers received free vaccines in exchange for data on doses administered. ${ }^{54}$ This approach will increase the accessibility of the HepB-BD vaccine for motherinfant pairs who seek care across different types of facilities.

\section{Community Level}

SSA countries are predominately rural, presenting a unique access-based barrier. In SSA, marginalized people who must travel more than 2 hours to access emergency public hospital facilities make up $29 \%$ of the population, of whom $28 \%$ are women of childbearing age. In fact, hospital facility access is only widely available in 16 of 48 African countries. ${ }^{55}$ South Sudan presents the most extreme case globally, with $75 \%$ of its population living further than a 2-hour walk away from a hospital facility. ${ }^{55}$ Given these statistics, immunization system strengthening cannot happen solely at centralized health facilities. Instead, efforts must also extend to reach mothers and newborns at the community level.

A high proportion of SSA infants are born at home and therefore do not have access to HepBBD. ${ }^{35,56}$ Low HepB-BD adherence rates are largely due to the lack of formal outreach programs to vaccinate newborns at home or to refer mother-
SSA countries that currently administer HepBBD also reported stock-outs as an implementation barrier. 


\section{A final approach overlooked in the HepB-BD-related literature is the use of home- based records as a potential solution to increase immunization coverage at the community level.}

infant pairs to nearby facilities. ${ }^{35,57}$ Another determinant is the lack of access to health facilities and trained CHWs to administer the vaccinations. Proposed solutions include improved maternal involvement, CHW involvement, and innovative technologies.

\section{Maternal Involvement}

The mother-infant pair is integral to the success of any immunization implementation approach. Health officials often consider at-home births inadvisable. However, most home births occur not because the mother refuses to visit a health facility but because she lacks access to a facility. ${ }^{58}$ Therefore, educating mothers about the importance of timely HepB-BD must occur at both the facility and the community levels. Decision makers should consider community-level interventions focused on health behaviors. For instance, cultural barriers may impact the time taken to bring an infant to a facility after delivery. In The Gambia and Nigeria, where at-home birth rates are high, mothers wait 7 days to name their infants before visiting a facility, hindering timely administration of HepB-BD. ${ }^{34}$

While the prevalence of home births may be attributed to cultural, religious, or access-related issues, most women eventually bring their newborns to facilities after birth. Health officials should consider leveraging these visits after a home birth to deliver HepB-BD as soon as possible and educate mothers about the importance of a timely visit.

Additional targeted interventions include raising awareness within communities and building trust by leveraging existing civil society networks, improving understanding, and reminding caregivers of the importance of HepB-BD. ${ }^{46}$ These initiatives allow the most crucial contributors in the implementation formula, the mothers, to have the resources necessary to understand the importance of timely vaccination.

Antenatal care facilities are an essential resource to educate pregnant women about the importance of HepB-BD. More than $90 \%$ of SSA women have had at least 1 antenatal care visit; this is an opportune time to teach women about in-facility delivery benefits and the importance of timely HepB-BD. ${ }^{34,35}$ However, communitybased educational initiatives should be simultaneously promoted by establishing a gathering place within a community or using radio or social media campaigns to disseminate vaccination information to expectant mothers. Exposure to information during pregnancy has a positive impact on HBV knowledge and can be achieved by incorporating targeted education programs or improving existing educational material to include targeted HepB-BD information. ${ }^{59}$ A Nigerian study delivered an educational initiative for expectant mothers, providing information on $\mathrm{HBV}$ burden in-country and across SSA, vaccine benefits, and the timing of the HepB-BD vaccine. ${ }^{33}$ The study found that immunization education and awareness successfully increased HepB-BD uptake. Information strategies should focus on the vaccine's safety and be delivered by CHWs to increase HepB-BD uptake. ${ }^{60}$

A final approach overlooked in the HepB-BDrelated literature is the use of home-based records as a potential solution to increase immunization coverage at the community level. Home-based records can facilitate mothers' knowledge and detection of health problems and can encourage continuity of care and completion of the 4 doses of HBV vaccine. ${ }^{61}$

\section{Community Health Worker Involvement}

Significant vaccination obstacles exist during athome births due in large part to fissures in communication between community members and health facilities. CHWs can bridge these fissures, improving vaccine awareness and knowledge in a community.

CHWs can act as intermediaries to provide relevant delivery and vaccination information to mothers, other family members, and health facilities. Notably, CHWs are a critical source of health information for pregnant women and mothers, as well as other community members, in rural locations. CHW-led home visits are vehicles for reaching women who do not have access to antenatal care in rural communities. ${ }^{46}$ Home visits allow skilled birth attendants to educate expectant mothers, identify potential births in the communities, attend the deliveries, ${ }^{34}$ promote institutional deliveries, ${ }^{12,62}$ and refer the mother-infant pair to nearby facilities for vaccination and other services. In addition, many SSA countries have regular outreach services to provide vaccinations and other services to children living in hard-to-reach villages. ${ }^{63} \mathrm{CHWs}$ may even travel to remote communities for scheduled visits and to provide door-todoor immunization for infants.

Given that CHWs are the liaison between communities and a health facility, strong communication ties between CHWs and health facilities are crucial to vaccine uptake. This importance is 
highlighted by relevant SEA studies, which reported a cost-effective and practical strategy through regular district-level training. CHWs visit health facilities to receive regular training and share learnings with their communities. ${ }^{46,52} \mathrm{~A}$ Republic of Kiribati study reported that educating CHWs led to an $18 \%$ increase in timely HepB-BD delivery across the island. ${ }^{52}$ CHWs can further advocate for HepB-BD by involving religious and community leaders and by engaging men and other family members to influence community norms and acceptance. ${ }^{45}$ CHWs play a vital role in the success of a vaccine intervention, and incentives to collaborate come either from having a stake in their community's well-being, from per-diems for vaccine interventions, ${ }^{64}$ or encouraging referral of mother-infant pairs to health facilities. ${ }^{45}$ CHWs are often the primary representative of the health care system at the community level. As such, their involvement is essential to ensure community buy-in of HepB-BD.

\section{Evidence-based Innovations to Reach Communities}

Beyond knowledge barriers, logistical barriers to HepB-BD delivery exist at the community level. HepB-BD coverage in rural communities remains low due to HepB-BD's cold-chain storage requirements; the vaccine must be kept between $2{ }^{\circ} \mathrm{C}$ and $8^{\circ} \mathrm{C}$. $^{37,52}$

Increased vaccine coverage is now possible due to scientific (use of out-of-cold-chain [OCC] or controlled-temperature chains) and technological (mHealth) innovations to address geographic barriers to access of HepB-BD.

Various studies have examined the advantages of vaccine storage at ambient temperature at the point of service delivery. ${ }^{45}$ Studies in SEA exploring solutions to reach rural at-home births found that HepB-BD can be kept OCC at a temperature of up to $37^{\circ} \mathrm{C}$ for 1 month without loss of potency. ${ }^{4,37,65}$ While some countries have used OCC approaches to transport other vaccines, ${ }^{66}$ this innovative approach is novel in SSA and has never been incorporated into a model to reach at-home births within a 24-hour window.

WHO recommends taking the OCC approach further by transporting and storing vaccines in stable temperature carriers-controlled-temperature chains (CTCs). ${ }^{45}$ This approach increases coverage, reduces resource wastage, and increases the outreach of HepB-BD. ${ }^{45}$ CTCs require several conditions to maintain the vaccine outside the traditional $2^{\circ} \mathrm{C}$ to $8^{\circ} \mathrm{C}$ cold chain, including single removal from the cold chain into temperatures not exceeding $40^{\circ} \mathrm{C} .^{45}$ Compared with the OCC approach, this innovation halves the cost, reduces the risk of freezing the vaccine, and more effectively protects vaccine quality. ${ }^{45}$ However, unlike traditional OCC technology, CTCs require additional CHW training. ${ }^{4}$ CTC trials conducted in Laos and the Solomon Islands tested the effect of CTCs for HepB-BD transport and storage and reported increases in vaccine uptake by $28 \%{ }^{67}$ (Laos) and $150 \%{ }^{68}$ (Solomon Islands). Delivering vaccines using CTCs has strong potential to increase vaccine coverage, especially in rural, hardto-reach communities. CTCs are not currently available as licenses and prequalifications are pending for HepB-BD. ${ }^{11,45}$

Studies have also reported coupling mHealth aspects with OCC methods for HepB-BD delivery. A Laos study used mobile phones provided to CHWs to track at-home deliveries, real-time stock-outs, and monitor cold-chain temperature following OCC vaccine delivery. The study demonstrated a significant improvement in the proportion of children receiving HepB-BD-related home visits. ${ }^{64}$ Multifaceted innovations could improve HepB-BD coverage in rural villages.

\section{DISCUSSION}

We summarize key determinants of HepB-BD implementation at the 3 levels of policy, facility, and community in SSA (Table 2). We highlight barriers to timely uptake of the vaccine at all levels, as well as evidence-based solutions to these barriers. Any implementation strategy for HepB-BD must consider all 3 levels and must be adapted to the local context. SSA countries should model their implementation strategies on the success stories of HepB-BD introduction in SEA. 52,59,60,64 There are a few key examples of successful HepBBD introduction in SSA, ${ }^{33,35,36}$ but there is much room for improvement since only 13 of 48 countries have incorporated HepB-BD into their routine vaccination schedules.

Several areas stand out as "low-hanging fruit" for further research and development. Although SSA countries acknowledge the need for buy-in for HepB-BD at the political and facility levels, health officials and researchers continuously understate the mother's role in HepB-BD implementation approaches. In Nigeria, Botswana, and The Gambia, where HepB-BD policies exist, ${ }^{39,64}$ the literature focuses predominately on results measured at the facility or national level, rather than at the community level. Notably, significant gaps 
exist in the literature when addressing the 3 sublevel themes discussed at the community level: maternal involvement, CHW involvement, and evidence-based innovations.

SSA is highly rural, and universal coverage of HepB-BD will prove impossible without reaching at-home births. We suggest future research be geared toward community-level HepB-BD implementation approaches leveraging CHWs and prioritizing mothers. Proposed research includes testing and leveraging evidence-based innovations already identified in $\mathrm{SEA}^{11,34,37,52}$ to improve vaccine reach to home births and involving mothers in the implementation process. Despite these potential benefits, existing literature does not address these service end-user approaches in a HepB-BD-specific context. Finally, scientific (OCC vaccines) and technological (mHealth) innovations can drastically improve vaccine uptake in at-home births.

Published literature on HepB-BD immunization implementation in SSA countries is limited, but success stories from diverse settings confirm that HepB$\mathrm{BD}$ is feasible. Synergy must exist between the 3 levels of policy, facility, and community for SSA countries to effectively implement a universal HepB-BD immunization policy. Literature about the mother's role at the community level is strikingly scarce, and efforts to leverage community-level resources have been limited. To achieve successful HepB-BD introduction in African settings, more attention must be paid both by policy makers and researchers to the mother's and the community's role in vaccine uptake.

Funding: JBP and MY report grants from the U.S. National Institutes of Health (NIH), outside the submitted work. PT is funded by grants from the $\mathrm{NIH}$ (K08Al1 48607) and Novavax (2019nCoV-301), outside of this work.

Author contributions: $A B$ performed the scoping review and wrote the first draft with contributions from PT, JBP, MY, and BF. AB and VG developed the tables and figure. All authors edited and revised the final manuscript and approve it in its final version.

Competing interests: PT and JBP report support from an American Society of Tropical Medicine and Hygiene/Burroughs-Wellcome Fund award and research support from Gilead Sciences. JBP reports research support from World Health Organization, nonfinancial support from Abbott Laboratories, and honoraria from Virology Education. All other authors report no potential conflicts.

\section{REFERENCES}

1. Hepatitis. World Health Organization Regional Office for Africa. Accessed December 16, 2021. https://wnw. afro.who.int/healthtopics/hepatitis

2. Hepatitis B. World Health Organization. July 27, 2021. Accessed December 16, 2021. https://www.who.int/news-room/factsheets/detail/hepatitis-b
3. World Health Organization Regional Office for Africa (WHO). Regional Strategic Plan for Immunization 2014-2020. WHO; 2014. Accessed December 16, 2021. https://www.afro.who.int/ publications/regional-strategic-plan-immunization-2014-2020

4. Breakwell L, Tevi-Benissan C, Childs L, Mihigo R, Tohme R. The status of hepatitis B control in the African region. Pan Afr Med J. 2017;27 (Suppl 3):17. CrossRef. Medline

5. Edmunds WJ, Medley GF, Nokes DJ, O'Callaghan CJ, Whittle HC Hall AJ. Epidemiological patterns of hepatitis B virus (HBV) in highly endemic areas. Epidemiol Infect. 1996;1 17(2):313-325. CrossRef. Medline

6. Keane E, Funk AL, Shimakawa Y. Systematic review with metaanalysis: the risk of mother-to-child transmission of hepatitis $B$ virus infection in sub-Saharan Africa. Aliment Pharmacol Ther. 2016;44 (10):1005-1017. CrossRef. Medline

7. Poovorawan $Y$, Sanpavat S, Pongpunlert W, Chumdermpadetsuk S, Sentrakul P, Safary A. Protective efficacy of a recombinant DNA hepatitis $B$ vaccine in neonates of $\mathrm{HBe}$ antigen-positive mothers. JAMA. 1989;261(22):3278-3281. CrossRef. Medline

8. Wong VCW, Ip HM, Reesink HW, et al. Prevention of the HBsAg carrier state in newborn infants of mothers who are chronic carriers of $\mathrm{HBsAg}$ and $\mathrm{HBeAg}$ by administration of hepatitis-B vaccine and hepatitis-B immunoglobulin. Double-blind randomised placebocontrolled study. Lancet. 1984;1(8383):921-926. CrossRef. Medline

9. Reardon JM, O'Connor SM, Niau JD, Lam EK, Staton CA, Cookson ST. Cost-effectiveness of birth-dose hepatitis $B$ vaccination among refugee populations in the African region: a series of case studies. Confl Health. 2019;13:5. CrossRef. Medline

10. Spearman CW, Afihene $M$, Ally R, et al. Hepatitis B in sub-Saharan Africa: strategies to achieve the 2030 elimination targets. Lancet Gastroenterol Hepatol. 2017;2(12):900-909. CrossRef. Medline

11. Dionne-Odom J, Niei B, Tita ATN. Elimination of vertical transmission of Hepatitis B in Africa: a review of available tools and new opportunities. Clin Ther. 2018;40(8):1255-1267. CrossRef. Medline

12. Nelson NP, Easterbrook PJ, McMahon BJ. Epidemiology of hepatitis $B$ virus infection and impact of vaccination on disease. Clin Liver Dis. 2016;20(4):607-628. CrossRef. Medline

13. Njuguna $H$. Building toward a future of African children free of HBV infection: hepatitis B virus infection in Africa. Presentation at: Gastroenterology Sub-Saharan Africa ECHO Clinic; November 23, 2021. Accessed January 4, 2021. https://www. globalhep.org/ sites/default/files/content/webinar/files/2021-12/NiugunaBuilding\%20Toward\%20a\%20Future\%20of\%20African\% 20Children\%20Free\%20of\%2OHBV\%2OInfection-\%2OHepatitis\% 20B\%20Virus\%20infection\%20in\%20Africa.pdf

14. Polaris Observatory Collaborators. Global prevalence, treatment, and prevention of hepatitis B virus infection in 2016: a modelling study. Lancet Gastroenterol Hepatol. 2018;3(6):383-403. CrossRef. Medline

15. Boa A, Douba A, N Guessan TB, et al. A plea for introduction of hepatitis B vaccination at birth in Côte d'lvoire. Article in French. Sante Publique. 2017;29(5):751-760. CrossRef. Medline

16. Chang $M-H$, Fischler $B$, Blauvelt $B$, et al. Survey of impediments to prevention of mother-to-infant transmission of hepatitis $B$ virus by international societies. J Pediatr Gastroenterol Nutr. 2019;69(6):648654. CrossRef. Medline

17. Ginzberg D, Wong RJ, Gish R. Global HBV burden: guesstimates and facts. Hepatol Int. 2018;12(4):315-329. CrossRef. Medline

18. Hambridge T, Nartey Y, Duah A, Plymoth A. Hepatitis B mother-tochild transmission in the eastern region of Ghana: a cross-sectional pilot study. Pan Afr Med J. 2019;33:1-9. CrossRef. Medline

19. Howell J, Lemoine $M$, Thursz M. Prevention of materno-foetal transmission of hepatitis B in sub-Saharan Africa: the evidence, current 
practice and future challenges. J Viral Hepat. 2014;21(6):381-396. CrossRef. Medline

20. Jourdain G, Ngo-Giang-Huong N, Khamduang W. Current progress in the prevention of mother-to-child transmission of hepatitis $B$ and resulting clinical and programmatic implications. Infect Drug Resist. 2019;12:977-987. CrossRef. Medline

21. Kolwaite AR, Xevatvongsa A, Ramirez-Gonzalez A, et al. Hepatitis B vaccine stored outside the cold chain setting: a pilot study in rural Lao PDR. Vaccine. 2016;34(28):3324-3330. CrossRef. Medline

22. Mak L-Y, Seto W-K, Fung J, Yuen M-F. Novel developments of hepatitis $B$ : treatment goals, agents and monitoring tools. Expert Rev Clin Pharmacol. 2019;12(2):109-120. CrossRef. Medline

23. Miyahara R, Jasseh M, Gomez P, et al. Barriers to timely administration of birth dose vaccines in The Gambia, West Africa. Vaccine. 2016;34(29):3335-3341. CrossRef. Medline

24. Nayagam S, Conteh L, Sicuri E, et al. Cost-effectiveness of community-based screening and treatment for chronic hepatitis B in The Gambia: an economic modelling analysis. Lancet Glob Heal. 2016;4(8):e568-e578. CrossRef. Medline

25. Nayagam S, Thursz M, Sicuri E, et al. Requirements for global elimination of hepatitis B: a modelling study. Lancet Infect Dis. 2016;16 (12):1399-1408. CrossRef. Medline

26. Nguyen Si Anh H, Vo HL, Hoang Bao L, Tran Minh H, Tran Thi Thu H, Kien VD. Hepatitis B birth dose vaccination among Vietnamese children: implications for the Expanded Program on Immunization. Biomed Res Int. 2019;2019:3453105. CrossRef. Medline

27. Pham TH, Le TX, Nguyen DT, et al. Knowledge, attitudes and medical practice regarding hepatitis $B$ prevention and management among healthcare workers in Northern Vietnam. PLoS One. 2019;14(10):1-15. CrossRef. Medline

28. Scott N, Palmer A, Morgan C, et al. Cost-effectiveness of the controlled temperature chain for the hepatitis $B$ virus birth dose vaccine in various global settings: a modelling study. Lancet Glob Heal. 2018;6 (6):e659-e667. CrossRef. Medline

29. Sobel HL, Mantaring JB 3rd, Cuevas F, et al. Implementing a national policy for hepatitis B birth dose vaccination in Philippines: lessons for improved delivery. Vaccine. 2011;29(5):941-945. CrossRef. Medline

30. Spearman $C W$. Towards the eliminataion of hepatitis $B$ and hepatocellular carcinoma. S Afr Med J. 2018;108(8b):13-16. CrossRef. Medline

31. Wiesen $E$, Lagani W, Sui G, et al. Assessment of the hepatitis B birth dose vaccination program, Papua New Guinea, 2014. Vaccine. 2016;34(3):367-372. CrossRef. Medline

32. World Health Organization. Hepatitis B vaccines: WHO position paper, July 2017 - recommendations. Vaccine. 2019;37(2):223225. CrossRef. Medline

33. Okenwa UJ, Dairo MD, Uba B, Ajumobi O. Maternal reasons for non-receipt of valid Hepatitis $B$ birth dose among mother-infant pairs attending routine immunization clinics, South-east, Nigeria. Vaccine. 2019;37(46):6894-6899. CrossRef. Medline

34. Breakwell L, Anga J, Dadari I, Sadr-Azodi N, Ogaoga D, Patel M. Evaluation of storing hepatitis $B$ vaccine outside the cold chain in the Solomon Islands: identifying opportunities and barriers to implementation. Vaccine. 2017;35(21):2770-2774. CrossRef. Medline

35. Moturi E, Tevi-Benissan C, Hagan J, et al. Implementing a birth dose of hepatitis $B$ vaccine in Africa: findings from assessments in 5 countries. J Immunol Sci. 2018; Suppl(5):31-40. CrossRef. Medline

36. Awuku Y, Yeboah-Afihene M. Hepatitis B at-birth dose vaccine: an urgent call for implementation in Ghana. Vaccines (Basel). 2018;6 (1):15. CrossRef. Medline

37. Tamandjou CR, Maponga TG, Chotun N, Preiser W, Andersson MI. Is hepatitis B birth dose vaccine needed in Africa? Pan Afr Med J. 2017;27(Suppl 3):18. CrossRef. Medline
38. Hepatitis B (HepB) vaccine price data. UNICEF. Accessed December 15, 2021. https://www.unicef.org/supply/documents/hepatitis-bhepb-vaccine-price-data

39. Hagan JE, Carvalho E, Souza V, et al. Selective hepatitis B birth-dose vaccination in São Tomé and Príncipe: a program assessment and cost-effectiveness study. Am J Trop Med Hyg. 2019;101(4):891898. CrossRef. Medline

40. Anderson S, Harper LM, Dionne-Odom J, Halle-Ekane G, Tita ATN A decision analytic model for prevention of hepatitis $B$ virus infection in Sub-Saharan Africa using birth-dose vaccination. Int J Gnaecol Obstet. 2018;141(1):126-132. CrossRef. Medline

41. The unique database on National Immunization Technical Advisory Groups. NRC. Accessed December 15, 2021. https://www.nitagresource.org/ Published 2020.

42. Founding of Philosophy NOPLHB. The National Organisation for People Living with Hepatitis B. Accessed December 15, 2021. https://noplhb.org/our-story/

43. Peterson HB, Haidar J, Fixsen D, Ramaswamy R, Weiner BJ, Leatherman S. Implementing innovations in global women's, children's, and adolescents' health: realizing the potential for implementation science. Obstet Gynecol. 2018;131(3):423-430. CrossRef. Medline

44. World Health Organization (WHO). The WHO Strategy on Research for Health. WHO; 2012. Accessed December 15, 2021. https://www.who.int/phi/WHO_Strategy_on_research_for_ health.pdf

45. World Health Organization (WHO). Preventing Perinatal Hepatitis B Virus Transmission: A Guide for Introducing and Strengthening Hepatitis B Birth Dose Vaccination. WHO; 2015. Accessed December 15, 2021. http://wnw.who.int/iris/handle/10665/ 208278

46. Adamu AA, Adamu AL, Dahiru Al, Uthman OA, Wiysonge CS. Mainstreaming implementation science into immunization systems in the decade of vaccines: a programmatic imperative for the African Region. Hum Vaccin Immunother. 2018;14(10):2443-2446. CrossRef. Medline

47. Beigi RH, Fortner KB, Munoz FM, et al. Maternal immunization: opportunities for scientific advancement. Clin Infect Dis. 2014;59 Suppl 7(Suppl 7):S408-S414. CrossRef. Medline

48. Bassoum O, Kimura M, Tal Dia A, Lemoine M, Shimakawa Y. Coverage and timeliness of birth dose vaccination in sub-Saharan Africa: a systematic review and meta-analysis. Vaccines (Basel). 2020;8(2):301. CrossRef. Medline

49. Zivich PN, Kiketa L, Kawende B, Lapika B, Yotebieng M. Vaccination coverage and timelines among children 0-6 months in Kinshasa, the Democratic Republic of Congo: a prospective cohort study. Matern Child Health J. 2017;21(5):1055-1064. CrossRef. Medline

50. Merten S, Chaignat C-L, Lapika B, et al. Sociocultural determinants of anticipated vaccine acceptance for acute watery diarrhea in early childhood in Katanga Province, Democratic Republic of Congo. Am J Trop Med Hyg. 2013;89(3):419-425. CrossRef. Medline

51. Thompson $P$, Morgan $C E$, Ngimbi $P$, et al. Arresting vertical transmission of hepatitis B virus (AVERT-HBV) in pregnant women and their neonates in the Democratic Republic of the Congo: a feasibility study. Lancet Glob Heal. 2021;9(11):e1600-e1609. CrossRef. Medline

52. Li X, Heffelfinger J, Wiesen $E$, et al. Improving hepatitis $B$ birth dose coverage through village health volunteer training and pregnant women education. Vaccine. 2017;35(34):4396-4401. CrossRef. Medline

53. Mwamba GN, Yoloyolo N, Masembe Y, et al. Vaccination coverage and factors influencing routine vaccination status in 12 high risk health zones in the province of Kinshasa City, Democratic Republic of Congo (DRC), 2015. Pan Afr Med J. 2017;27(Suppl 3):7. CrossRef. Medline 
54. Patel MK, Capeding RZ, Ducusin JU, de Quiroz Castro M, Garcia LC, Hennessey K. Findings from a hepatitis B birth dose assessment in health facilities in the Philippines: opportunities to engage the private sector. Vaccine. 2014;32(39):5140-5144. CrossRef. Medline

55. Ouma PO, Maina J, Thuranira PN, et al. Access to emergency hospital care provided by the public sector in sub-Saharan Africa in 2015: a geocoded inventory and spatial analysis. Lancet Glob Health. 2018;6(3):e342-e350. CrossRef. Medline

56. Lemoine $M$, Thursz MR. Battlefield against hepatitis $B$ infection and HCC in Africa. J Hepatol. 2017;66(3):645-654. CrossRef. Medline

57. Centers for Disease Control and Prevention (CDC). Hepatitis B vaccine birthdose practices in a country where hepatitis $B$ is endemic - Laos, December 2011-February 2012. MMWR Morb Mortal Wkly Rep. 2013;62(29):587-590. Medline

58. Odutola A, Afolabi MO, Ogundare EO, et al. Risk factors for delay in age-appropriate vaccinations among Gambian children. BMC Health Serv Res. 2015;15(1):346. CrossRef. Medline

59. Hang Pham TT, Le TX, Nguyen DT, et al. Knowledge, attitudes and medical practice regarding hepatitis $B$ prevention and management among healthcare workers in Northern Vietnam. PLoS One. 2019;14(10):e0223733. CrossRef. Medline

60. Giao H, Quang Vinh B, Huynh Tam Lang N, Le An P. Parents' attitude about hepatitis $B$ disease and practice of hepatitis $B$ vaccination among children in Ho Chi Minh City, Vietnam. BioMed Res Int. 2019;2019:932814. CrossRef. Medline

61. World Health Organization (WHO). Packages of Interventions for Family Planning, Safe Abortion Care, Maternal, Newborn, and Child Health. WHO; 2010. Accessed December 15, 2021. https:// apps.who.int/iris/handle/10665/70428
62. Woodring J, Pastore R, Brink A, Ishikawa N, Takashima Y, Tohme RA. Progress toward hepatitis $B$ control and elimination of mother-tochild transmission of hepatitis B virus - Western Pacific Region, 2005-2017. MMWR Morb Mortal Wkly Rep. 2019;68(8):195200. CrossRef. Medline

63. Périères $L$, Marcellin F, Lo $G$, et al. Hepatitis B vaccination in Senegalese children: coverage, timeliness, and sociodemographic determinants of non-adherence to immunisation schedules (ANRS 12356 AmBASS Survey). Vaccines (Basel). 2021;9(5):510. CrossRef. Medline

64. Xeuatvongsa A, Datta SS, Moturi E, et al. Improving hepatitis B birth dose in rural Lao People's Democratic Republic through the use of mobile phones to facilitate communication. Vaccine. 2016;34 (47):5777-5784. CrossRef. Medline

65. Centers for Disease Control and Prevention (CDC). Perinatal Quality Collaborative Success Story. CDC; 2016. Accessed December 15, 2021. https://www.cdc.gov/reproductivehealth/ maternalinfanthealth/pdf/ohio-success-story_508tagged.pdf

66. Zipursky S, Dijngarey MH, Lodjo JC, Olodo L, Tiendrebeogo S, Ronveaux $\mathrm{O}$. Benefits of using vaccines out of the cold chain: delivering meningitis $A$ vaccine in a controlled temperature chain during the mass immunization campaign in Benin. Vaccine. 2014;32 (13):1431-1435. CrossRef. Medline

67. Thinking outside the box: innovations in preventing hepatitis $B$ at birth. Centers for Disease Control and Prevention. Accessed December 15, 2021. https://www.cdc.gov/globalhealth/ immunization/stories/laos-hep-b-vax.htm

68. Wiesen E, Diorditsa S, Li X. Progress towards hepatitis B prevention through vaccination in the Western Pacific, 1990-2014. Vaccine. 2016;34(25):2855-2862. CrossRef. Medline

\section{Peer Reviewed}

Received: April 1, 2021; Accepted: October 27, 2021; First published online: January 21, 2022.

Cite this article as: Boisson A, Goel V, Yotebieng M, Parr JB, Fried B, Thompson P. Implementation approaches for introducing and overcoming barriers to hepatitis B birth-dose vaccine in sub-saharan Africa. Glob Health Sci Pract. 2022;10(1):e2100277. https://doi.org/10.9745/GHSP-D-21-00277

(c) Boisson et al. This is an open-access article distributed under the terms of the Creative Commons Attribution 4.0 International License (CC BY 4.0), which permits unrestricted use, distribution, and reproduction in any medium, provided the original author and source are properly cited. To view a copy of the license, visit https://creativecommons. org/licenses/by/4.0/. When linking to this article, please use the following permanent link: https:// doi.org/10.9745/GHSP-D-21-00277 